\title{
Comparison of Subacromial Ketorolac Injection Vs Subacromial Steroid Injection in the treatment of Shoulder Impingement Syndrome
}

\author{
TARIQ SIDDIQUE ${ }^{1}$, HAIDER AYYAZ HARL 2 , SYED FARAZ UL HASSAN SHAH GILLANI ${ }^{3}$, SADIA ASIF ${ }^{4}$, MIAN \\ MUHAMMAD HANIF 5 \\ 1,2Senior registrar Orthopedic Surgery, King Edward Medical University, Mayo Hospital, Lahore \\ ${ }^{3}$ Senior Registrar Rheumatology, Fatima Memorial Hospital, Lahore \\ Correspondence to Dr. Tariq Siddique, Email:drtariqsiddiq@gmail.com, Cell.03324112773
}

\begin{abstract}
Aim: To compare the outcome of subacromial ketorolac injection versus subacromial steroid injection in Shoulder Impingement Syndrome.

Methodology: This randomized controlled trial was done at the Department of Orthopedics Unit II, Mayo Hospital, Lahore from $26^{\text {th }}$ April 2018 to $25^{\text {th }}$ October 2018. The sample size was 218 patients 15 to 60 years of age with shoulder impingement syndrome, were included and patients with a fracture or rotator cuff tear who presented with weakness and muscle wasting, taking regular systemic NSAIDs or steroids, history ofgastrointestinal (GI) ulcers and bleeding disorderswereexcluded. Randomization was done by lottery method.Group A (ketorolac group) was given a single injection of $60 \mathrm{mg}$ ketorolac mixed with $1 \mathrm{ml} 2 \%$ lidocaine and Group B (steroid group) was given $40 \mathrm{mg}$ methylprednisolone mixed with $1 \mathrm{ml} 2 \%$ lidocaine. All patients were followed up on $4^{\text {th }}$ weeks.

Results: Out of 218 patients, $117(53.67 \%)$ were males and $101(46.33 \%)$ were females with a male to female ratio of 1.2:1. The mean age of patients in group A was $39.09 \pm 9.90$ years and in group, B was $38.08 \pm 8.61$ years. The mean post-injection VAS score in group A was $2.80 \pm 0.94$ and in a group, B was $4.20 \pm 0.98$ with a p-value of $<0.001$. The mean post-injection constant score in group $A$ was $31.59 \pm 6.86$ and in group, $B$ was $41.31 \pm 4.56$ with a p-value of $<0.001$.

Conclusion: Sub-acromial ketorolac injection showeda better mean pain score and constant score than subacromial steroid injection in patients with shoulder impingement syndrome.

Keywords: Shoulder Impingement Syndrome, subacromial ketorolac injection, subacromial steroid injection,
\end{abstract}

\section{INTRODUCTION}

Periarticular shoulder disorder refers to a set of diverse diseases including subacromial and subdeltoid bursitis, rotator cuff tendinitis, calcific tendinitis, and rotator cuff tear with or without adhesive capsulitis leading to shoulder pain and restricted range of motion (ROM) ${ }^{1}$. Patient present with pain on elevating the arm or when lying on the affected side. Shoulder pain is the third most common musculoskeletal complaint in orthopaedic practice, ${ }^{2}$ and impingement syndrome is one of the more common underlying diagnoses. On a pathophysiological basis, it can have various functional, degenerative, and mechanical causes. The impingement hypothesis assumes a pathophysiological mechanism in which different structures of the shoulder joint come into mechanical conflict ${ }^{2}$.

A representative cross-sectional study has shown that approximately $30 \%$ of the Finnish population over age 30 suffers from occasional or persistent shoulder pain in the course of a single month ${ }^{3}$. Another study has shown that $16 \%$ of the population has shoulder pain in one month. Peak incidence is during the sixth decade of life. ${ }^{4}$ The most common clinical diagnoses are rotator cuff defects (85\%) and/or impingement syndromes (74\%). The prevalence of rotator cuff defects rises with age. Up to $30 \%$ of persons over age 70 have a total defect, but $75 \%$ of such cases are asymptomatic ${ }^{4}$. The goal of treatment is to eliminate pain and restore joint function. Good and very good results can be achieved with conservative and surgical methods in

Received on 07-01-2021

Accepted on 27-04-2021 approximately $80 \%$ of cases $^{5}$. There are still no valid measuring instruments or prospective studies showing which patients stand to benefit from conservative treatment or surgery $6,7,8$. There is as yet no German guideline on this topic; a Dutch guideline on subacromial pain was issued in $2014^{9}$. Shoulder impingement syndrome is usually treated conservatively including resting, non-steroidal antiinflammatory drugs (NSAIDs), sub-acromial injections (corticosteroids, local anaesthetics, hyaluronate and recently tenoxicam), suprascapular nerve blockage, and physical and manual therapy ${ }^{10,11}$.

Steroid injections are widely utilized and are a well accepted method of treatment for patients with subacromial impingement syndrome who have not responded to more conservative therapies ${ }^{12,13}$. Since steroids are effective mainly because of their anti inflammatory properties, there is an argument to use local injections of NSAIDs to decrease inflammation in the subacromial space. There is evidence that subacromial injections of NSAIDs may provide pain relief and restoration of function in shoulder impingement syndrome. Ketorolac is an NSAID that acts by inhibiting the synthesis of prostaglandins which is used for the treatment of moderate to severe pain ${ }^{14,16}$.

The study objective was to compare the treatment outcome of two groups in terms of pain and function.

\section{MATERIALS AND METHODS}

This randomized controlled trial was done using a probability simple random sampling technique in the Department of Orthopedics Unit II, Mayo Hospital, Lahore from $26^{\text {th }}$ April 2018 to $25^{\text {th }}$ October 2018 . The sample size 
was 218 patients, aged between 15 to 60 years with shoulder impingement syndrome for a duration of more than one month were included and patients withprior operations of the shoulder joint, fracture or a major tear of the rotator cuff presenting with weakness and muscle wasting, injection in the same shoulder within the previous 2 months, taking regular systemic NSAIDs or steroids and gastrointestinal ulcers or bleeding disorders were excluded.

After approval from the local ethical committee, informed written consent was obtained from all the patients. Shoulder Impingement Syndrome was defined as patients with a history of pain (VAS $=3-10$ ) with passive and active abduction and positive Neer sign and Hawkins-Kennedy test (elevate the patient's arm to test for reproducible pain) was taken as positive. All patients were offered to pick up a slip from total mixed up slips (half-slips contained the letter ' $A$ ' and the other half slips contained the letter ' $B$ ') and he/she was placed in that respective group. Group $A$ (ketorolac group) was given a single injection of $60 \mathrm{mg}$ ketorolac mixed with $1 \mathrm{ml} \mathrm{2 \%}$ lidocaine and Group B (steroid group) was given $40 \mathrm{mg}$ methylprednisolone mixed with $1 \mathrm{ml} \mathrm{2 \%} \mathrm{lidocaine.} \mathrm{The} \mathrm{outcome} \mathrm{was} \mathrm{measured} \mathrm{after} 4$ weeks of subacromial injection in terms of following i.e. Mean Pain score, it was assessed by a visual analogue scale with 0 no pain and 10 worst pain. Mean Constant's score was assessed for function evaluation (pain, activity level, and range of motion with standard goniometry).

Statistical analysis was performed using SPSS version 20.0. Mean and standard deviation was calculated for age, BMI, duration of disease, pre-injection and postinjection VAS score and constant's score. Frequencies and percentages were calculated for gender and diabetes mellitus (yes/no). An independent sample t-test was used to compare post-injection VAS score and constant's score in both groups and a p-value of $\leq 0.05$ was taken as significant. $\mathrm{P}$-value $\leq 0.05$ was considered significant.

\section{RESULTS}

Out of 218 patients, $117(53.67 \%)$ were males and $101(46.33 \%)$ were females with a male to female ratio of 1.2:1. In group-A, there were $54(49.54 \%)$ male and $55(50.46 \%)$ female cases while in group B there were $63(57.80 \%)$ male and $46(42.20 \%)$ female cases. The mean age in group-A and group-B was $39.09 \pm 9.90$ years and $38.08 \pm 8.61$ years. The mean $B M l$ in group- $A$ was $29.07 \pm 2.60$ and in group, B was 29.32 \pm 2.31 . The age, gender and BMI distribution were statistically the same in both study groups, $p$-value $>0.05$.

The mean pain at baseline in group-A was $6.34 \pm 1.34$ and in group-B was $6.61 \pm 1.10$ on the visual analogue score with no significant difference, $p$-value $>0.05$. After treatment the mean pain was statistically less in group- $A$ $(2.8 \pm 0.94)$ when compared with group-B $(4.2 \pm 0.98)$, pvalue $<0.001$. The mean constant score in group- $A$ and group-B was statistically same at baseline i.e. $66.49 \pm 10.85$ and 65.99 \pm 9.91 respectively, $p$-value $>0.05$ while after treatment the mean constant score was statistically less in group-A (31.59 \pm 6.86$)$ as compared to group-B (41.31 \pm 4.56$),$ p-value $<0.001$.

Table-l: comparison of demographic and clinical parameters in both groups

\begin{tabular}{|l|c|c|c|}
\hline & Group A (n=109) & Group B (n=109) & p-value \\
\hline Age (years) & $39.09 \pm 9.90$ & $38.08 \pm 8.61$ & $>0.05$ \\
\hline BMl & $29.07 \pm 2.60$ & $29.32 \pm 2.31$ & $>0.05$ \\
\hline Pain baseline & $6.34 \pm 1.34$ & $6.61 \pm 1.10$ & $>0.05$ \\
\hline Mean pain post injection & $2.8 \pm 0.94$ & $4.2 \pm 0.98$ & $<0.001$ \\
\hline Constant score baseline & $66.49 \pm 10.85$ & $65.99 \pm 9.91$ & $>0.05$ \\
\hline Constant score Post injection & $31.59 \pm 6.86$ & $41.31 \pm 4.56$ & $<0.001$ \\
\hline
\end{tabular}

\section{DISCUSSION}

Periarticular shoulder disorder refers to a set of diverse diseases including subacromial and subdeltoid bursitis, rotator cuff tendinitis, calcific tendinitis, and rotator cuff tear with or without adhesive capsulitis leading to shoulder pain and restricted range of motion (ROM) ${ }^{17,18}$. Shoulder impingement syndrome is usually treated conservatively including resting, NSAIDs, subacromial injections (corticosteroids, local anaesthetics, hyaluronate and recently tenoxicam), suprascapular nerve blockage, and physical and manual therapy ${ }^{19-22}$.

This study was conducted to compare the outcome of subacromial ketorolac injection versus subacromial steroid injection in Shoulder Impingement Syndrome. The age range in this study was from 15 to 60 years with a mean age of $28.53 \pm 9.42$ years. The mean age of patients in group A was $39.09 \pm 9.90$ years and in group, B was $38.08 \pm 8.61$ years. The majority of the patients $118(54.13 \%)$ were between 31 to 40 years of age. Out of 218 patients, $117(53.67 \%)$ were males and 101 (46.33\%) were females with a male to female ratio of $1.2: 1$. The mean post-injection
VAS score in group A was $2.80 \pm 0.94$ and in a group, B was $4.20 \pm 0.98$ with a $p$-value of $<0.001$. The mean postinjection constant score in group $A$ was $31.59 \pm 6.86$ and in group, B was $41.31 \pm 4.56$ with a $p$-value of $<0.001$. In a study, the mean post-injection VAS score at 4 weeks was $3.75 \pm 1.71$ in the steroid group while $4.45 \pm 1.96$ in the ketorolac group. Similarly, the constant's score for function assessment was $29.1 \pm 17.70$ and $36.9 \pm 19.42$ respectively ${ }^{16}$. Min et al compared the efficacy of a single subacromial injection of ketorolac with a single injection of methylprednisolone in 32 patients with impingement syndrome. They found that ketorolac was equally effective in the treatment of shoulder impingement with better improvement in the University of California at Los Angeles (UCLA) shoulder scores during a 4-week follow-up ${ }^{23}$.

Min et al performed the same study on 48 patients and showed that, at 4 weeks, a ketorolac injection had better efficacy than triamcinolone injections, as proved by the improvements of the UCLA Shoulder Assessment Score, forward flexion strength, and patient satisfaction ${ }^{24}$. Karthikeyan et $\mathrm{al}^{25}$ compared the efficacy of a single 
subacromial injection of tenoxicam, with a single injection of methylprednisolone in patients with impingement syndrome. Although tenoxicam injection exerted positive effects, they found significantly greater improvements in the methylprednisolone group. Their results were different from our study and this could be due to the low potency of analgesic effect of tenoxicam compared to methylprednisolone or ketorolac.

In a study 26 twenty patients with shoulder impingement syndrome received an injection of $60 \mathrm{mg}$ ketorolac and were evaluated in terms of visual analogue scale (VAS), range of motion (ROM) and Constant-Murley score. The outcomes are compared with the data of patients treated by $40 \mathrm{mg}$ triamcinolone injection, retrospectively. There was no significant difference in the demographics, VAS, ROM, and Constant-Murley score between the two groups before the injection. At the 4 weeks follow-up, pain improvement was significantly greater in the corticosteroid group $(2.7 \pm 1.53)$ than in the ketorolac group $(4.9 \pm 2.08 ; \mathrm{p}<0.001)$. However 12 weeks after the injection, there was no significant difference in pain improvement between the two groups (ketorolac: 2.9 \pm 2.32 , corticosteroid: $2.6 \pm 1.82 ; p=0.707)$. The ConstantMurley score at the final follow-up improved from 33.5 to 52.1 in the corticosteroid group, and from 39.0 to 56.6 in the ketorolac group $(p=0.677)$. ROM was increased in both groups, and external rotation was significantly greater in the ketorolac group than in the corticosteroid group at the final follow-up (ketorolac: $29.3^{\circ} \pm 9.90^{\circ}$, corticosteroid: $\left.20.8^{\circ} \pm 7.99^{\circ} ; \mathrm{p}=0.005\right)^{26}$. In another study, where subacromial corticosteroid injection was given in shoulder impingement syndrome showed overall improvement in $31(91.2 \%)$ patient with three out of 31 required the second dose of injection till last follow-up ( $p$-value $<0.001)^{27}$.

In another study ${ }^{1}$, forty patients having shoulder impingement syndrome with findings of rotator cuff tendinitis or subacromial bursitis on magnetic resonance imaging were included in the study. Patients were randomized into two subacromial injection groups: patients in the first group (10 males, 10 females; mean age 45.3 years; range 32 to 67 years) were administered $20 \mathrm{mg}$ tenoxicam three times by weekly intervals, and patients in the second group ( 8 males, 12 females; mean age 46.5 years; range 29 to 73 years) were administered $40 \mathrm{mg}$ methylprednisolone acetate just for once. Visual analogue scale (VAS), active range of motion (ROM) of the shoulder joint, and Disabilities of Arm, Shoulder and Hand (DASH) questionnaire scores were evaluated at baseline, six weeks after treatment, and the first year. Visual analogue scale, DASH, and active ROM scores in both groups were statistically significantly improved. No statistically significant difference was detected between subacromialtenoxicam and steroid injections in terms of post-treatment VAS, DASH, and active ROM scores. Mean pre-and posttreatment VAS scores in the tenoxicam group were 7.8 (range, 3-9) and 2.6 (range, 2-4), respectively. Mean preand post-treatment VAS scores in the steroid group were 6.2 (range, 3-10) and 3.6 (range, 0-7), respectively. Mean pre-and post-treatment DASH scores in the tenoxicam group were 59.4 (range, 45-80) and 14.7 (range, 8.3-25.8), respectively. Mean pre-and post-treatment DASH scores in the steroid group were 56.7 (range, 33.3-85.8) and 18.1 (range, 0-69.2), respectively. Although the improvement in active ROM was higher in the steroid group, the difference between the two groups was not statistically significant. ${ }^{1}$

\section{CONCLUSION}

This study concluded that subacromial ketorolac injection shows a better mean pain score and constant score than subacromial steroid injection in patients with Shoulder Impingement Syndrome. So, we recommend that subacromial ketorolac injection should be used routinely in patients with Shoulder Impingement Syndrome to reduce their morbidity.

\section{REFERENCES}

1. Çift H, Özkan F, Tolu S, Şeker A, Mahiroğulları M. Comparison of subacromial tenoxicam and steroid injections in the treatment of impingement syndrome. Eklem Hastalik Cerrahisi. 2015;26(1):16-20.

2. Habermeyer $\mathrm{P}$, Lichtenberg $\mathrm{S}$, Magosch $\mathrm{P}$, editors. Schulterchirurgie. " Elsevier, Urban\&FischerVerlag"; 2011 May 11.

3. Mäkelä $M$, Heliövaara $M$, Sainio $P$, Knekt $P$, Impivaara $O$, Aromaa A. Shoulder joint impairment among Finns aged 30 years or over: prevalence, risk factors and co-morbidity. Rheumatology. 1999;38(7):656-62.

4. Yamaguchi K, Ditsios K, Middleton WD, Hildebolt CF, Galatz LM, Teefey SA. The demographic and morphological features of rotator cuff disease. A comparison of asymptomatic and symptomatic shoulders. J Bone Joint Surg Am. 2006;88(8):1699-704.

5. Wurnig C. [Shoulder impingement]. Orthopade. 2000;29(10):868-80.

6. Dorrestijn O, Stevens M, Winters JC, van der Meer K, Diercks $R L$. Conservative or surgical treatment for subacromial impingement syndrome? A systematic review. J Shoulder Elbow Surg. 2009;18(4):652-60.

7. Tashjian RZ. Is there evidence in favor of surgical interventions for the subacromial impingement syndrome? Clin J Sport Med. 2013;23(5):406-7.

8. Saltychev M, Äärimaa V, Virolainen P, Laimi K. Conservative treatment or surgery for shoulder impingement: systematic review and meta-analysis. Disabil Rehabil. 2015;37(1):1-8.

9. Diercks R, Bron C, Dorrestijn O, Meskers C, Naber R, de Ruiter $\mathrm{T}$, et al. Guideline for diagnosis and treatment of subacromial pain syndrome: a multidisciplinary review by the Dutch Orthopaedic Association. Acta Orthop. 2014;85(3):31422.

10. Steuri R, Sattelmayer M, Elsig S, Kolly C, Tal A, Taeymans J, et al. Effectiveness of conservative interventions including exercise, manual therapy and medical management in adults with shoulder impingement: a systematic review and metaanalysis of RCTs. Br J Sports Med. 2017;51(18):1340-7.

11. Kwon J LY, Kim HM, Kim JM, Jung HS, Yi SR. Early Clinical Outcomes after Subacromial Injection of Ketorolac in Patients with Shoulder Impingement Syndrome: A Comparison with Steroid Injection. J Korean Orthop Associ. 2017;52(2):170-7.

12. Maman E, Yehuda C, Pritsch T, Morag G, Brosh T, Sharfman $Z$, et al. Detrimental Effect of Repeated and Single Subacromial Corticosteroid Injections on the Intact and Injured Rotator Cuff: A Biomechanical and Imaging Study in Rats. Am J Sports Med. 2016;44(1):177-82.

13. Byun SD, Hong YH, Hong SK, Song JW, Woo SB, Noh JH, et al. Effects of repeated steroid injection at subacromial bursa with different interval. Ann Rehabil Med. 2014;38(6):805-11.

14. Vadivelu N, Gowda AM, Urman RD, Jolly S, Kodumudi V, Maria M, et al. Ketorolac tromethamine - routes and clinical implications. Pain Pract. 2015;15(2):175-93. 
15. Devereaux M, Velanoski KQ, Pennings A, Elmaraghy A. ShortTerm Effectiveness of Precut Kinesiology Tape Versus an NSAID as Adjuvant Treatment to Exercise for Subacromial Impingement: A Randomized Controlled Trial. Clin J Sport Med. 2016;26(1):24-32.

16. Taheri P, Dehghan F, Mousavi S, Solouki R. Comparison of Subacromial Ketorolac Injection versus Corticosteroid Injection in the Treatment of Shoulder Impingement Syndrome. J Res Pharm Pract. 2017;6(4):223-7.

17. Kim SB, Yoon K, Park HS, Kwak H, Ha NJ, Park JS, et al. Ultrasonography in the Shoulder Impingement Syndrome. J Korean Acad Rehabil Med 2000;24(3):542-50.

18. Ulaşlı AM, Erkeç S, Uyar S, Nacır B, Yılmaz Ö, Erdem HR. The effect of acromioclavicular joint degeneration on orthopedic shoulder tests. Eklem Hastalik Cerrahisi. 2013;24(2):77-81.

19. Naredo E, Cabero F, Beneyto P, Cruz A, Mondéjar B, Uson J, et al. A randomized comparative study of short term response to blind injection versus sonographic-guided injection of local corticosteroids in patients with painful shoulder. J Rheumatol. 2004;31(2):308-14.

20. Chen MJ, Lew HL, Hsu TC, Tsai WC, Lin WC, Tang SF, et al. Ultrasound-guided shoulder injections in the treatment of subacromial bursitis. Am J Phys Med Rehabil. 2006;85(1):315.

21. Blair B, Rokito AS, Cuomo F, Jarolem K, Zuckerman JD. Efficacy of injections of corticosteroids for subacromial impingement syndrome. J Bone Joint Surg Am. 1996;78(11):1685-9.
22. Düzgün I, Baltaci G, Atay OA. Manual therapy is an effective treatment for frozen shoulder in diabetics: an observational study. Eklem Hastalik Cerrahisi. 2012;23(2):94-9.

23. Min KS, St Pierre P, Ryan PM, Marchant BG, Wilson CJ, Arrington ED. A double-blind randomized controlled trial comparing the effects of subacromial injection with corticosteroid versus NSAID in patients with shoulder impingement syndrome. J Shoulder Elbow Surg. 2013;22(5):595-601.

24. Min K, Ryan P, Marchant B, Arrington E. A double-blinded randomized controlled clinical trial comparing the efficacy of subacromial injection of ketorolac versus triamcinolone in the treatment of subacromial impingement syndrome. Annual Meeting. 2017:206.

25. Karthikeyan S, Kwong HT, Upadhyay PK, Parsons N, Drew SJ, Griffin D. A double-blind randomised controlled study comparing subacromial injection of tenoxicam or methylprednisolone in patients with subacromial impingement. J Bone Joint Surg Br. 2010;92(1):77-82.

26. Kwon J, Lee YH, Kim HM, Kim JM, Jung HS, Yi SR. Early Clinical Outcomes after Subacromial Injection of Ketorolac in Patients with Shoulder Impingement Syndrome: A Comparison with Steroid Injection. J Korean Orthop Assoc. 2017;52(2):1707.

27. Akram M, Gillani SFuHS, Farooqi FM, Awais SM. Acromion Types and Role of Corticosteroid with Shoulder Impingement Syndrome. J Coll Phy Surg Pak 2016; 26 (12): 980-3. 